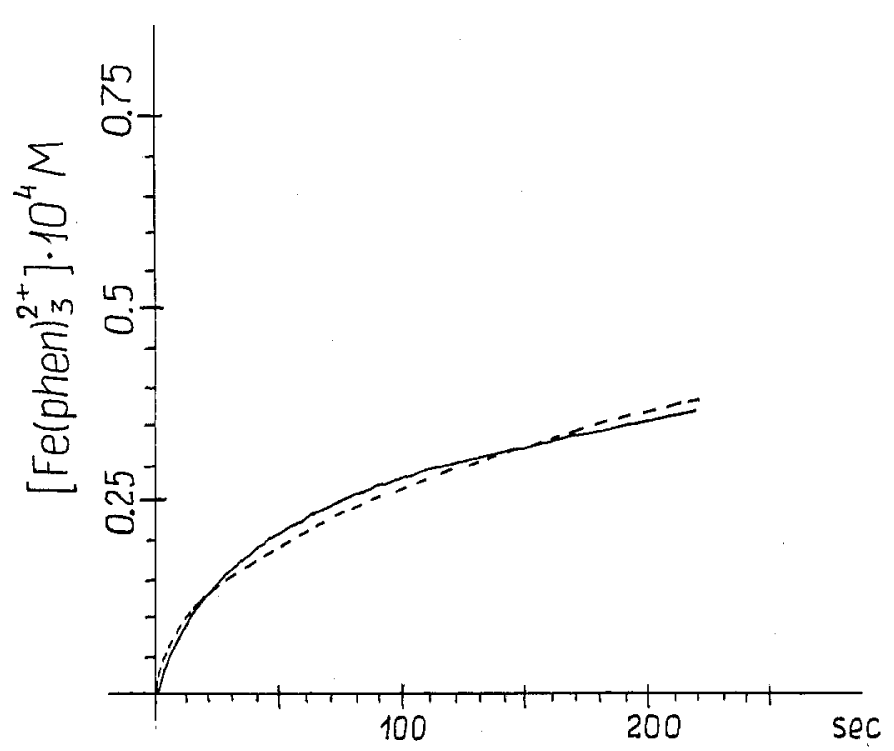

Figure 1. $\mathrm{Fe}$ (phen) ${ }_{3}{ }^{2+}$ production during bromomalonic acid oxidation by $\mathrm{Fe}(\mathrm{phen}){ }_{3}{ }^{3+}$. Solid line is the experiment, broken line is calculated from expression 3: $[\mathrm{BMA}]=6.25 \times 10^{-3} \mathrm{M} ;\left[\mathrm{Fe}(\text { phen })_{3}{ }^{3+}\right]_{0}=1.25 \times$ $10^{-4} \mathrm{M} ;\left[\mathrm{H}_{2} \mathrm{SO}_{4}\right]=1.5 \mathrm{M}\left(h_{0}=3.65 \mathrm{M}\right)$. The following values were ascribed to the constants in (3): $k_{1}=10 \mathrm{M}^{-1} \mathrm{sec}^{-1}, k_{-1} / k_{2}=5 \times 10^{5}$ $\mathrm{M}^{-2}$.

of the acidity function $h_{0}$ instead of the proton concentration $\left[\mathrm{H}^{+}\right]$ is reasonable at high concentrations of $\mathrm{H}_{2} \mathrm{SO}_{4}\left(\left[\mathrm{H}_{2} \mathrm{SO}_{4}\right]>0.1\right.$ M). ${ }^{16,17}$

Expression 3 with appropriate values for the rate constants provides a fairly good approximation to the observed kinetics

(16) Hammett, L. P. “Physical Organic Chemistry”; McGraw-Hill: New York, 1970 .

(17) "Handbook of Chemistry"; Nauka: Moscow, 1971; Vol. 3.
(Figure 1, dotted line)

To evaluate the constants in (3) from the experimental data, we used the Marquardt technique. ${ }^{18}$ This procedure reveals that the best agreement with experiment is reached when $k_{-1}$ is so large that $k_{-1} h_{0} x$ in (3) is much greater than $k_{2}$ almost within the whole range of $x$ variation. In such a case $K=k_{2} k_{1} / k_{-1}$ is the only constant determining rate expression 3. Therefore reliable estimates are obtained only for the constant $K$. The values of $K$, averaged over the results of five runs for each set of initial concentrations, are given in Table $\mathrm{I}$.

The lower limit for $k_{1}$ was also estimated: $k_{1}>1 \mathrm{M}^{-1} \mathrm{~s}^{-1}$.

Littler and Sayce ${ }^{11}$ mentioned the ferriin reduction by malonic acid as a first order-reaction in $\mathrm{Fe}$ (phen) ${ }_{3}{ }^{3+}$ concentration. If it is so, the reason for the difference in kinetics of these two similar reactions is still to be clarified.

The results show that the rate of the $\mathrm{Fe}$ (phen) ${ }_{3}{ }^{3+}$ reduction by BMA decreases very rapidly with the accumulation of the reduced from of the catalyst $\mathrm{Fe}$ (phen $)_{3}{ }^{2+}$. The slowing down can be accounted for by the reverse reaction (eq -1). This is the most probable reason for the fact that in the ferroin-catalyzed oscillatory reaction the phase of catalyst reduction is much longer than that of catalyst oxidation, while in the cerium-catalyzed one the two phase are comparable.

These results can contribute to a better understanding of the oscillation mechanism and pattern formation in the ferroin-catalyzed Belousov-Zhabotinsky system. They should be taken into account when constructing a mathematical model of these phenomena.

Acknowledgment. I am much obliged to the reviewer who called my attention to the ref 11 and 12 .

Registry No. Ferroin, 14708-99-7; bromomalonic acid, 600-31-7. Wiley: New York, 1970.

\title{
Proton Magic Angle Spinning Nuclear Magnetic Resonance and Temperature Programmed Desorption Studies of Ammonia on the Acidity of the Framework Hydroxyl Groups in the Zeolite H-ZSM-5 and in H-Boralite
}

\author{
K. F. M. G. J. Scholle, A. P. M. Kentgens, W. S. Veeman,* \\ Department of Physical Chemistry, University of Nijmegen, Toernooiveld, 6525 ED Nijmegen, \\ The Netherlands \\ P. Frenken, and G. P. M. van der Velden
}

DSM-Central Laboratories, 6160 MD Geleen, The Netherlands (Received: September 29, 1983)

\begin{abstract}
The acidity of the framework hydroxyl groups of H-ZSM-5 and H-boralite is investigated by means of proton magic angle spinning NMR and temperature programmed desorption of $\mathrm{NH}_{3}\left(\mathrm{NH}_{3}-\mathrm{TPD}\right)$. The acidity decreases on going from $\mathrm{Si}-\mathrm{OH}-\mathrm{Al}$, the Bronsted acidic site in $\mathrm{H}-\mathrm{ZSM}-5$, to $\mathrm{Si}-\mathrm{OH}-\mathrm{B}$, the Bronsted acidic site in $\mathrm{H}$-boralite, to $\mathrm{Si}-\mathrm{OH}$, the terminating hydroxyl group of the zeolite lattice (silanol group). The sequence is in agreement with the $\mathrm{NH}_{3}$-TPD results.
\end{abstract}

\section{Introduction}

Knowledge of the acidity of the framework hydroxyl groups is of great importance in catalysis by zeolites. ${ }^{1}$ Several methods are used to determine the acidity of solids, e.g., temperature programmed desorption of $\mathrm{NH}_{3}\left(\mathrm{NH}_{3}-\mathrm{TPD}\right),{ }^{2}$ titration with

(1) P. A. Jacobs, "Carboniogenic Activity of Zeolites", Elsevier, Amsterdam, 1977.

(2) N. Topsøe, K. Pedersen, and E. G. Derouane, J. Catal, 70, 41 (1981).
Hammett indicators, ${ }^{3}$ infrared spectroscopy, ${ }^{4}$ or ${ }^{13} \mathrm{C} \mathrm{NMR}^{5}$ with the use of probe molecules. Recently, ${ }^{1} \mathrm{H}$ magic angle spinning NMR (MAS NMR) has been applied to the study of hydroxyl groups in zeolites ${ }^{6,7}$ and in silica gel. ${ }^{8}$ Freude, Hunger, and

(3) K. Tanabe, "Solid Acid and Bases", Academic Press, New York, 1970.

(4) J. Ward, Adv. Chem. Ser., No. 101, 380 (1970).

(5) H. J. Rauscher, D. Michel, D. Deininger, and D. Geschke, J. Mol. Catal., 9, 369 (1980). 
Pfeifer ${ }^{6}$ have shown for zeolites that the positions of the $\mathrm{OH}$ resonances in the NMR spectrum are related to the acidity of the proton. In this report, the acidity of zeolite H-ZSM-5 and of $\mathrm{H}$-boralite is compared by application of ${ }^{1} \mathrm{H}$ MAS NMR and $\mathrm{NH}_{3}$-TPD.

Zeolite H-ZSM-5 was discovered by Mobil Oil and has potential applications in the synthesis of gasoline from alcohols., 90 Boralites are crystalline borosilicates with zeolite-like structures. In our case boralite has a zeolite ZSM-5-like structure, but because of its composition it is not considered to be a zeolite. ${ }^{11}$

The acidity can be defined as the residual charge of the hydrogen atom of the hydroxyl group or as the ease with which the proton can be dissociated ${ }^{12,13}$ (the Bronsted definition). The proton chemical shift is a measure of the screening of the proton nuclear spin by electrons and thus related to the proton acidity of the hydroxyl group. The more acidic the proton, the lower the resonance field..$^{14}$ In solids like zeolites, the proton line widths can be large due to dipolar couplings of the proton to neighboring spins $\left({ }^{1} \mathrm{H},{ }^{27} \mathrm{Al},{ }^{29} \mathrm{Si},{ }^{11} \mathrm{~B}\right)$ and due to the anisotropy of the proton chemical shift. The proton line width, therefore, has to be reduced by solid-state NMR line narrowing techniques like multiple pulse sequences ${ }^{15}$ and/or magic angle spinning. ${ }^{16}$ Due to an apparent local mobility of the protons, in our case magic angle spinning alone was sufficient to eliminate all line broadening due to anisotropic interactions like the dipolar coupling and chemical shift.

After the physically adsorbed water molecules were dissolved, the resulting spectrum, as reported earlier, ${ }^{6,7}$ consists of two NMR lines. The low-field resonance signal is assigned to protons in Bronsted acidic sites ( $\mathrm{Si}-\mathrm{OH}-\mathrm{Al}$ ) and water molecules chemisorbed at these sites. The high-field resonance signal comes from protons of the silanol groups $(\mathrm{Si}-\mathrm{OH})$ and water molecules around these groups. By comparison of the chemical shifts of the resonance signals an acidity sequence can be derived for the structural hydroxyl groups in H-ZSM-5 and H-boralite.

On the basis of the simple electrostatic valence model of Pauling ${ }^{17}$ this acidity sequence is discussed.

\section{Experimental Section}

Preparation of the Samples. The ZSM-5 sample (010277) was prepared according to a general method described by a Mobil Oil patent. ${ }^{18}$ Synthesis and applications are described in recent literature. ${ }^{19-22}$ In the synthesis of $\mathrm{H}$-boralite a mixture of 112.6 $\mathrm{g}$ of $\mathrm{SiO}_{2}$ (Aerosol 200 by Degussa) in $1011 \mathrm{~mL}$ of $20 \%$ tetrapropylammonium hydroxide (by Fluka) and of $23.4 \mathrm{~g}$ of $\mathrm{H}_{3} \mathrm{BO}_{3}$ in $789 \mathrm{~g}$ of $\mathrm{H}_{2} \mathrm{O}$ was subjected to a hydrothermal treatment at $150^{\circ} \mathrm{C}$ in a Hastelloy-C metal autoclave for 8 days. The obtained solid product was washed, dried, and calcined in air at $500^{\circ} \mathrm{C}$

(6) D. Freude, M. Hunger, and H. Pfeifer, Chem. Phys. Lett., 91, 307 (1982)

(7) K. F. M. G. J. Scholle, W. S. Veeman, J. G. Post, and J. H. C. van Hooff; Zeolites, 3, 214 (1983).

(8) H. Rosenberger, H. Ernst, G. Scheler, I. Jünger, and R. Sonnenberger, Z. Phys. Chem. (Leipzig), 263, 846 (1982).

(9) C. D. Chang and A. J. Silvestri, J. Catal., 47, 249 (1977)

(10) C. R. Morgan, Ind. Eng. Chem. Prod. Res. Dev., 20, 185 (1981).

(11) D. W. Breck, "Zeolite Molecular Sieves", Wiley, New York, 1973, p 47.

(12) S. Beran, P. Jíru, and B. Wichterlovå, J. Phys. Chem., 85, 1951 (1981). C. Zhixing, W. Zhengwu, H. Ruiyu, and Z. Yala, J. Catal., 79, 271 (1983).

(13) P. A. Jacobs, Catal. Rev. Sci. Eng., 24, 415 (1982)

(14) H. Rosenberger and A. R. Grimmer, Z. Anorg. Allg. Chem., 448, 11 (1979)

(15) U. Haeberlen, "High Resolution NMR in Solids-Selective Averaging", Supplement 1, Academic Press, New York, 1967.

(16) E. R. Andrew, Prog. Nucl. Magn. Res. Spectrosc., 8, 1 (1971).

(17) L. Pauling, "The Nature of the Chemical Bond", Cornell University Press, New York, 1980.

(18) US Patent 3702886, assigned to Mobil Oil.

(19) NL Patent 77-11299, assigned to Standard Oil.

(20) NL Patent 79-04909, assigned to Snamprogetti s.p.a.

(21) EP Patent 11900, assinged to Stamicarbon (DSM).

(22) M. Taramasso, "Proceedings of the Fifth International Conference on Zeolites", Rees, Ed., Heyden, London, 1980, p 40-8.

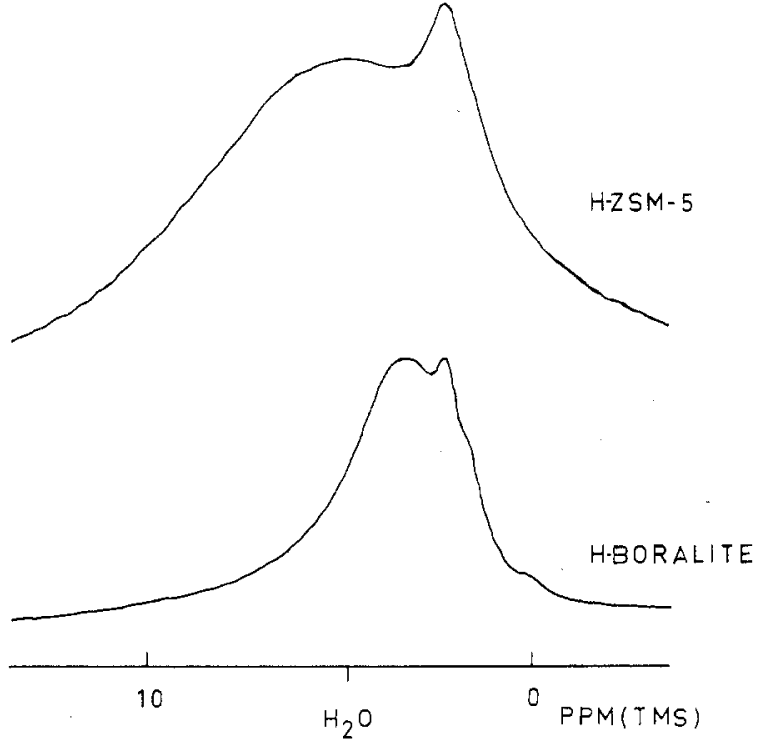

Figure 1. The ${ }^{1} \mathrm{H}$ MAS NMR spectra of dried H-ZSM-5 (sample 010277 , vacuum dried for $9 \mathrm{~h}$ at $230^{\circ} \mathrm{C}$, number of transients ca. 6000) and partly hydrated $\mathrm{H}$-boralite (vacuum dried for $15 \mathrm{~h}$ at $290^{\circ} \mathrm{C}$ and subsequently contacted with water vapour for $15 \mathrm{~min}$, number of transients ca. 8000 ). The signal at $\sim 0 \mathrm{ppm}$ is due to an impurity in the spinner.

and used without further treatments for ion exchange. X-ray diffusion measurements confirmed the crystalline character of all samples, which exhibited the typical diffraction pattern of zeolite ZSM-5. ${ }^{18}$ For the H-boralite sample the same symmetry as for ZSM-5 was found, but small differences in the unit cell dimensions exist. Chemical analyses of the samples yield the following compositions: $\mathrm{H}-\mathrm{ZSM}-5$ (010277), $\mathrm{SiO}_{2} / \mathrm{Al}_{2} \mathrm{O}_{3}=102$; $\mathrm{Na}_{2} \mathrm{O} / \mathrm{Al}_{2} \mathrm{O}_{3}=0.11 ; \mathrm{H}$-boralite, $\mathrm{SiO}_{2} / \mathrm{B}_{2} \mathrm{O}_{3}=220 ; \mathrm{Na}_{2} \mathrm{O} / \mathrm{B}_{2} \mathrm{O}_{3}$ $<0.2$.

TPD Techniques. $\mathrm{NH}_{3}$-TPD measurements were carried out with a Perkin-Elmer TGS-2 thermobalance. Adsorption of $\mathrm{NH}_{3}$ on the samples was carried out at $50^{\circ} \mathrm{C}$ with a $5 \mathrm{vol} \% \mathrm{NH}_{3}$ in He flow. After saturation of the catalyst by $\mathrm{NH}_{3}$ the physisorbed material was removed by stripping with $\mathrm{He}$ at the adsorption temperature. The chemically adsorbed material was removed by increasing the temperature at a heating rate of $10^{\circ} \mathrm{C} / \mathrm{min}$ and the amount was determined gravimetrically. The results are presented in a differential mode. From the TPD results adsorption enthalpies can be calculated by the method of Cvetanovic and Amenomiya. ${ }^{23}$ It will be clear, however, that the temperatures belonging to the peak maxima are representative of the adsorption enthalpy and, consequently, the acidity.

Procedures of Dehydration and Hydration for NMR Measurements. The procedures for hydration and dehydration of the samples were recently described. ${ }^{7}$

NMR Techniques. the ${ }^{1} \mathrm{H}$ NMR spectra were measured on a $180-\mathrm{MHz}$ FT spectrometer. ${ }^{24}$ The samples were spun at the magic angle at frequencies up to $4 \mathrm{kHz}$ in a cylindrical double air-bearing KEL-F spinner. ${ }^{25}$ The magic angle spinners were filled under an anhydrous nitrogen gas atmosphere in a glove box.

\section{Results and Discussion}

${ }^{1} H$ MAS NMR of $H-Z S M-5$ and $H$-Boralite. An untreated H-ZSM-5 sample gives one resonance signal right at the free $\mathrm{H}_{2} \mathrm{O}$ position due to the large amount of physically adsorbed water in the channels and at the outer surface of the zeolite. After the sample was dehydrated, a two-line NMR spectrum is observed (see Figure 1). As reported earlier, ${ }^{7}$ the low-field resonance signal

(23) R. J. Cvetanovic and Y. Amenomiya, Adv. Catal. Related Subjects, 17, 103 (1967)

(24) W. S. Veeman, E. M. Menger, W. Ritchey, and E. de Boer, Macromolecules, 12, 924 (1979).

(25) P. A. S, van Dijk, W. Schut, J. W. M. van Os, E. M. Menger, and W. S. Veeman, J. Phys. E, 13, 1309 (1980). 
at $\sim 6 \mathrm{ppm}$ (relative to $\mathrm{Me}_{4} \mathrm{Si}$ ) is assigned to protons in Bronsted acidic sites $(\mathrm{Si}-\mathrm{OH}-\mathrm{Al})$ and water molecules chemisorbed at these sites. The high-field resonance signal at $\sim 2 \mathrm{ppm}$ comes from protons of the silanol groups $(\mathrm{Si}-\mathrm{OH})$ and water molecules around these groups.

The absolute and relative intensities of the two resonances, which depend on the amount of water adsorbed, are discussed in ref 7. Here we want to concentrate on the line positions, which show no dependence on the amount of adsorbed water. It is well-known from liquid solution studies ${ }^{26}$ and from wide-line NMR studies of other zeolite-water systems, ${ }^{27}$ Linde A and faujasites, that the protons of water adsorbed at an adsorption site and the proton of the adsorption site itself exchange very rapidly. The chemical shift of such a fast exchange group, $\delta$, is given by ${ }^{28}$

$$
\delta=\frac{2 n}{2 n+1} \delta_{\mathrm{H}_{2} \mathrm{O}}+\frac{1}{2 n+1} \delta_{\mathrm{ZOH}}
$$

with $n$ the number of water molecules in the water cluster at the adsorption site, $\delta_{\mathrm{H}_{2} \mathrm{O}}$ the chemical shift of free liquid water, and $\delta_{\mathrm{ZOH}}$ the chemical shift of the adsorption site alone. This clearly shows that in the presence of adsorption sites the water position $(\delta)$ is shifted due to exchange with a proton with a different chemical shift $\left(\delta_{\mathrm{ZOH}}\right)$.

The sign of the shift, upfield or downfield, depends on whether $\delta_{\mathrm{ZOH}}$ is smaller than or greater than $\delta_{\mathrm{H}_{2} \mathrm{O}}$. The low-field resonance due to protons of and water molecules adsorbed at Bronsted sites, being at low field relative to the resonance of free $\mathrm{H}_{2} \mathrm{O}$, immediately makes clear that the resonance of the bare Bronsted site, which we never observed, must be at lower field than the resonance of free water. This is in contrast to the bare silanol group which should be found upfield from free water. This demonstrates that, due to its shift to higher field, silanol groups are considerably less acidic than Bronsted acidic sites, in agreement with other investigations. ${ }^{2,29}$ Proton magic angle spinning NMR thus provide a clue for the study of acidity in zeolites.

Possible exchange between Bronsted sites in the pores and silanol groups is not taken into account here. Fast exchange, at rates faster than the NMR time scale $\left(\tau^{-1} \sim 700 \mathrm{~Hz}\right)$, does not occur since otherwise one coalesced signal would be observed. Any slow exchange does not change the arguments.

Another zeolite-like system whose proton spectrum can be compared to that of $\mathrm{H}-\mathrm{ZSM}-5$ is $\mathrm{H}$-boralite. An untreated $\mathrm{H}$-boralite sample gives one resonance signal at the $\mathrm{H}_{2} \mathrm{O}$ position, clearly due, as in the case of $\mathrm{H}-\mathrm{ZSM}-5$, to the phycially adsorbed water in the channels and at the outer surface. Drying the sample reveals only one asymmetrical NMR signal consisting of at least two components. The high-field component at $\sim 2 \mathrm{ppm}$, by comparison with H-ZSM-5 and silicalite, ${ }^{7}$ can be attributed to the fast exchanging groups of protons of the water clusters at the silanol groups. After adsorbing a certain amount of water the low-field component at $\sim 3.5 \mathrm{ppm}$ manifests itself more clearly (see Figure 1); this signal increases in intensity but does not shift as more water is adsorbed. The low-field resonance signal is due to, as in the case of $\mathrm{H}-\mathrm{ZSM}-5$, the group of exchanging protons of the water cluster, and the proton of the Bronsted acidic site of $\mathrm{H}$-boralite ( $\mathrm{Si}-\mathrm{OH}-\mathrm{B})$. That the low-field resonance signal was not clearly observed after drying is probably caused by the high Si:B ratio $(\sim 110)$ and the position of the line of the dehydrated Bronsted acidic site (vide infra).

If we compare the chemical shifts of the low- and high-field resonance signals of $\mathrm{H}$-boralite with those of H-ZSM-5 (see Figure 1 and Figure 2 in which, schematically, the shifts of the low-field resonance signals of both solid catalysts are drawn), then

(26) R. P. Bell, "The Proton in Chemistry", Chapman and Hall, London, 1973.

(27) See for instance H. Pfeifer, "NMR Basic Principles and ProgressGrundlagen und Fortschritte", Vol. 7, P. Diehl, E. Fluck, and R. Kosfeld, Ed., Springer-Verlag, 1972, and references therein.

(28) H. S. Gutowsky and A. Saika, J. Chem. Phys., 21, 1688 (1953).

(29) J. C. Vedrine, A. Aroux, V. Bolis, P. Dejaifve, C. Naccache, P. Wierzchwoski, E. G. Derouane, J. B. Nagy, J. P. Gilson, J. H. C. von Hooff, J. P. van den Berg, and J. P. Wolthuizen, J. Catal., 59, 248 (1979).

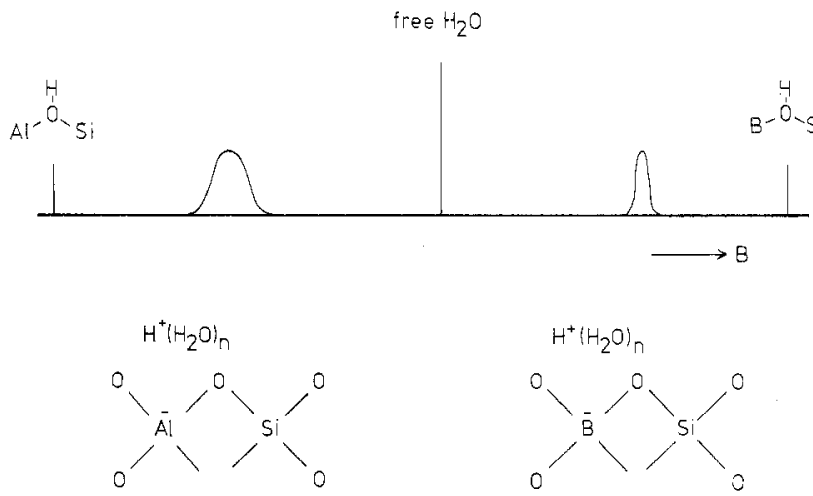

Figure 2. A qualitative plot of the shifts (relative to liquid water) of the resonance signals of the hydrated and bare Bronsted acidic sites in $\mathrm{H}-$ ZSM-5 and $\mathrm{H}$-boralite.

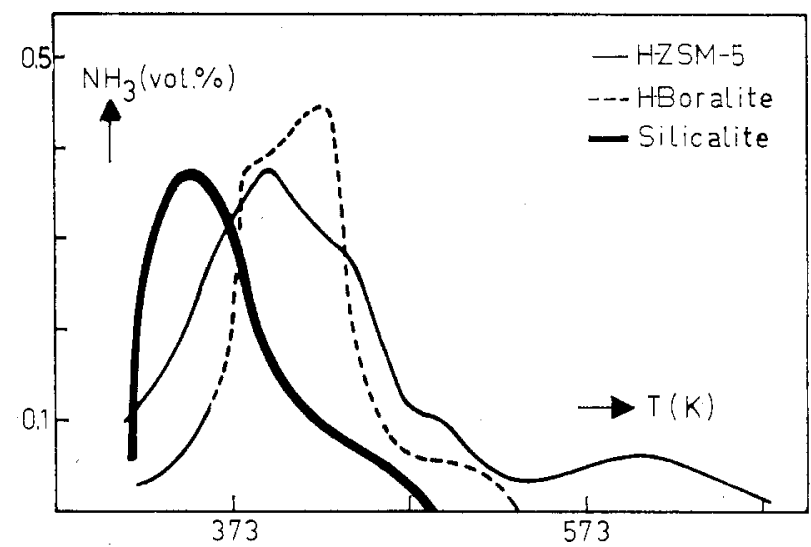

Figure 3. $\mathrm{NH}_{3}$-TPD graphs of $\mathrm{H}-\mathrm{ZSM}-5$ (010277), H-boralite, and a crystalline silica silicalite.

it can be seen that the chemical shifts of the high-field resonance signals (silanol groups) are the same but that the chemical shift of the low-field resonance signal of $\mathrm{H}$-boralite is shifted to higher field relative to the low-field resonance signal of H-ZSM-5 and to water.

Whatever the mechanism for the averaging of the chemical shift of the proton in the water cluster and the Bronsted acidic proton may be, simple exchange as assumed for eq 1 or a more complicated process, it is believed to be true for both H-ZSM-5 and $\mathrm{H}$-boralite that the resonance line of these protons will lie between the resonance value for free $\mathrm{H}_{2} \mathrm{O}$ and the resonance position of the dehydrated Bronsted proton. The Bronsted resonance line for partly hydrated H-ZSM-5 lies at lower field than that of free $\mathrm{H}_{2} \mathrm{O}$, while the Bronsted line for partly hydrated $\mathrm{H}$-boralite is found at a higher field than free $\mathrm{H}_{2} \mathrm{O}$. Consequently, the Bronsted line in dehydrated $\mathrm{H}$-boralite ( $\mathrm{Si}-\mathrm{OH}-\mathrm{B})$ must be found at a higher field than that of $\mathrm{H}-\mathrm{ZSM}-5$ ( $\mathrm{Si}-\mathrm{OH}-\mathrm{Al}$ ) (see Figure 2). This proves that (due to its shift to higher field) $\mathrm{H}$-boralite is less acidic than H-ZSM-5. The exact nature of the line widths of the ${ }^{1} \mathbf{H}$ NMR spectra will be dealt with in a future paper.

TPD Measurements. The results of the $\mathrm{NH}_{3}$-TPD measurements for H-ZSM-5, H-boralite, and a crystalline silicalite are shown in Figure 3. It is clear from this figure that most $\mathrm{NH}_{3}$ desorbs at the same temperature for all three samples. However, at temperatures above $573 \mathrm{~K}$ still some $\mathrm{NH}_{3}$ is adsorbed on $\mathrm{H}-\mathrm{ZSM}-5$, in contrast to $\mathrm{H}$-boralite and silicalite. This shows that in H-ZSM-5 sites are present which are more acidic than all sites in $\mathrm{H}$-boralite. Because the difference between $\mathrm{H}-\mathrm{ZSM}-5$ and $\mathrm{H}$-boralite consists of the $\mathrm{Al}$ and $\mathrm{B}$ Bronsted sites, this implies that the H-ZSM-5 Bronsted site is more acidic than the $\mathrm{H}-$ boralite Bronsted site. This confirms the results from MAS ${ }^{1} \mathrm{H}$ NMR.

Discussion. As was concluded, the acidity of the hydroxyl groups decreases in the order $\mathrm{Si}-\mathrm{OH}-\mathrm{Al}, \mathrm{Si}-\mathrm{OH}-\mathrm{B}$, and $\mathrm{SiOH}$. This means that the bond strength (Bronsted definition) of the $\mathrm{O}-\mathrm{H}$ bond increases in the same order. This indicates that by 
<smiles>CO[Si](C)(OC)O[TeH]</smiles><smiles></smiles><smiles>CO[Si](O)(O)OC</smiles>

Figure 4. The three types of framework hydroxyl groups: Bronsted acidic site in H-ZSM-5 (I), Bronsted acidic site in $\mathrm{H}$-boralite (II), and silanol group (III). The four types of bonds are indicated as $\mathrm{Si}-\mathrm{O}(-)$, $\mathrm{O}-\mathrm{H}(--), \mathrm{Al}-\mathrm{O}(-)$, and B-O (--):

replacing $\mathrm{Al}$ by $\mathrm{B}$ the Bronsted acidic site has more silanol character.

The difference in bond strength between $\mathrm{Si}-\mathrm{OH}-\mathrm{Al}$ and $\mathrm{SiOH}$ can be understood on the basis of the qualitative electrostatic valence model of Pauling. ${ }^{17}$ In this model the bond strength, $S$, between the cation and each anion around it is defined as the charge (valence) on the cation, $e Z_{c}$, divided by the coordination number $V$

$$
S=Z_{\mathrm{c}} / V
$$

and the charge of an anion, $-e Z_{\mathrm{a}}$, as the sum of the bond strengths of all bonds of the anion

$$
Z_{\mathrm{a}}=\sum_{i} S_{i}
$$

The bond strength of the $\mathrm{Si}-\mathrm{O}$ bond, $S_{(\mathrm{Si}-\mathrm{O})}$ (see Figure 4), is then equal to 1 .

According to eq 3 the charge on the oxygen atom of the silanol $\mathrm{OH}$ group is equal to the sum of the bond strength of the $\mathrm{O}-\mathrm{H}$ bond $S_{(\mathrm{O}-\mathrm{H})}$ and the $\mathrm{Si}-\mathrm{O}$ bond $S_{(\mathrm{Si}-\mathrm{O})}$ :

$$
Z_{\mathrm{O}}=2=S_{(\mathrm{Si}-\mathrm{O})}+S_{(\mathrm{O}-\mathrm{H})}
$$

The bond strength of the $\mathrm{O}-\mathrm{H}$ bond in the silanol group is then equal to 1 .

A similar calculation can be followed for the Bronsted acidic site. The bond strength of the $\mathrm{Al}-\mathrm{O}$ bond in a tetrahedral unit, $S_{(\mathrm{Al}-\mathrm{O})}$, as calculated by eq 2 , is equal to $3 / 4$; and the charge on the shared oxygen, see Figure 4, is the sum of the three bond strengths $S_{(\mathrm{Si}-\mathrm{O})}, S_{(\mathrm{Al}-\mathrm{O})}$, and $S_{(\mathrm{O}-\mathrm{H})}$ :

$$
Z_{0}=2=S_{(\mathrm{Si}-\mathrm{O})}+S_{(\mathrm{Al}-\mathrm{O})}+S_{(\mathrm{O}-\mathrm{H})}
$$

The bond strength of the $\mathrm{O}-\mathrm{H}$ bond in a Bronsted acidic site is then $1 / 4$, appreciably lower than the bond strength of the $\mathrm{O}-\mathrm{H}$ bond in a silanol group, in agreement with our measurements. The bond strength of the $\mathrm{O}-\mathrm{H}$ bond of the Bronsted acidic site in $\mathrm{H}$-boralite is, according to the same calculation, also $1 / 4$. However, as can be seen from eq 5 , the bond strength of the $\mathrm{O}-\mathrm{H}$ in boralite would increase if the $S_{(\mathrm{B}-\mathrm{O})}$ bond strength decreases. ${ }^{11} \mathrm{~B}$ and ${ }^{27} \mathrm{Al}$ NMR results seem to indicate that $S_{(\mathrm{Al}-\mathrm{O})}$ indeed is greater than $S_{(\mathrm{B}-0) \cdot}{ }^{30,31}$ Also, the Pauling electronegativity ${ }^{17,32}$ difference between oxygen $(\mathrm{EN}=3.5)$ and boron $(\mathrm{EN}=2.0)$ is less than the difference between oxygen and aluminum (EN $=1.5)$, so that it can be expected that the bond strength $S_{(\mathrm{B}-\mathrm{O})}$ is less than $S_{(\mathrm{Al}-\mathrm{O})}$. Then, according to eq 5 , the bond strength of the $\mathrm{O}-\mathrm{H}$ bond in the Bronsted acidic site of $\mathrm{H}$-boralite will be somewhat greater than the one in H-ZSM-5, in agreement with our ${ }^{1} \mathrm{H}$ NMR and $\mathrm{NH}_{3}$-TPD results.

\section{Conclusions}

From NMR studies and temperature programmed $\mathrm{NH}_{3}$ desorption it is concluded that the Bronsted acidic site in H-ZSM-5 is more acidic than in $\mathrm{H}$-boralite, while these sites in turn are more acidic than the silanol group. This acidity sequence can be understood by a simple electrostatic model.

Acknowledgment. We thank Mr. J. W. M. van Os for his skillful technical assistance, P. van Oeffelt (DSM) for his $\mathrm{NH}_{3}$-TPD measurements, and Prof. dr. E. de Boer for critically reading the manuscript. K. F. M. G. J. Scholle gratefully acknowledges financial support by DSM, Geleen, The Netherlands.

Registry No. $\mathrm{NH}_{3}, 7664-41-7$.

(30) A. P. M. Kentgens, K. F. M. G. J. Scholle, and W. S. Veeman, $J$. Phys. Chem., 87, 4357 (1983).

(31) K. F. M. G. J. Scholle and W. S. Veeman, manuscript in preparation.

(32) F. A. Cotton and G. Wilkinson, "Advanced Inorganic Chemistry", 3rd ed, Interscience, New York, 1972.

\title{
Angle-Resolved Surface Raman Scattering
}

\author{
David R. Mullins and Alan Campion*† \\ Department of Chemistry, University of Texas, Austin. Texas 78712 (Received: October 5, 1983)
}

\begin{abstract}
We have measured the angular distribution of the Raman scattered radiation from benzene adsorbed on $\mathrm{Ag}(111)$ at submonolayer coverage. The results agree well with predictions of a classical electrodynamical analysis where the primary and scattered electromagnetic fields are calculated from Fresnel's equations. These measurements may be used to determine the symmetries of the vibrational modes of adsorbed molecules, as well as their orientation on the surface.
\end{abstract}

\section{Introduction}

Vibrational spectroscopy is beginning to play an important role in modern surface chemistry-much as it has for years in many other areas of chemistry. In particular, several methods are now sensitive enough to obtain vibrational spectra of molecules adsorbed at submonolayer coverage on the low-area single-crystal surfaces that are widely used as model catalysts. These include infrared reflection-absorption, ${ }^{1}$ high-resolution electron energy loss (EELS), ${ }^{2}$ surface-enhanced Raman scattering (SERS), ${ }^{3}$ and, more recently, surface Raman spectroscopy without enhancement. ${ }^{4}$

\footnotetext{
${ }^{+}$Camille and Henry Dreyfus Teacher-Scholar and Alfred P. Sloan Research Fellow.
}

These methods have respective strengths and weaknesses, but to be useful probes of surface structure and dynamical processes, their excitation mechanisms and resulting surface selection rules must be understood.

The surface selection rule for infrared reflection-absorption spectroscopy on metal surfaces is well understood. ${ }^{5}$ At infrared

(1) M. J. Dignam and J. Fedyk, Appl. Spectrosc. Rev., 14, 249 (1979).

(2) H. Ibach and D. L. Mills, "Electron Energy Loss Spectroscopy and Surface Vibrations", Academic Press, New York, 1982.

(3) R. Chang and T. E. Furtak, Eds., "Surface Enhanced Raman Scattering", Plenum Press, New York, 1982.

(4) A. Campion, J. K. Brown, and V. M. Grizzle, Surf. Sci., 115, L153 (1982). 